\title{
Organic acids in two Portuguese chestnut (Castanea sativa Miller) varieties
}

\author{
Bárbara Ribeiro a , Joana Rangel a, Patrícia Valentão a , Paula B. Andrade a, \\ José Alberto Pereira ${ }^{b}$, Hanna Bölke ${ }^{\text {a }}$, Rosa M. Seabra ${ }^{\text {a,* }}$ \\ ${ }^{a}$ REQUIMTE/Serviço de Farmacognosia, Faculdade de Farmácia, Universidade do Porto, R. Aníbal Cunha, 164, 4050-047 Porto, Portugal \\ b CIMOIESAB, Quinta de Sta Apolónia, Apartado 1172, 5301-855 Bragança, Portugal
}

Received 18 July 2005; accepted 20 September 2005

\begin{abstract}
The organic acids composition of two different chestnut (Castanea sativa Miller) varieties (Judia and Longal) were determined by HPLC/UV. In order to check the influence of the processing over these compounds, samples treated in three distinct manners (roasted, boiled and fried) were also analysed. The results showed that chestnut is characterized by the presence of seven organic acids: oxalic, cisaconitic, citric, ascorbic, malic, quinic and fumaric acids. The organic acid quantitative profile allows the distinction of the two varieties. Longal variety samples presented higher organic acids contents than those from Judia variety. The contents of the pair malic plus quinic acids may be useful for the discrimination of the two varieties. Roasting, boiling and frying procedures lead to significant reduction of total organic acids contents.
\end{abstract}

(C) 2005 Elsevier Ltd. All rights reserved.

Keywords: Chestnut; Castanea sativa; Judia; Longal; Processing; Organic acids

\section{Introduction}

Among the 12 world chestnuts species, Castanea sativa Miller is the most consumed. This species is predominant in Portugal, where it has a relevant place at the socioeconomic level, reaching an annual fruit production of 20000 tons (Goulão, Valdiviesso, Santana, \& Oliveira, 2001). The best development conditions are found at altitudes higher than $500 \mathrm{~m}$ and winter low temperatures, as in the Bragança region (Northeast of Portugal) in which 12,500 ha are used for chestnuts cultivation. In fact, this region gives origin to chestnuts with Denomination d'Origine Protégé (DOP), called "Castanha da Terra Fria". Cultivation is almost limited to Judia and Longal varieties because of their higher nutritional qualities and greater commercial value. The fruits become ripe around Octo-

\footnotetext{
${ }^{*}$ Corresponding author. Tel.: +351 222078934; fax: +351 222003977.

E-mail address: rseabra@ff.up.pt (R.M. Seabra).
}

ber/November and are mainly consumed roasted, boiled and fried.

From a nutritional point of view, chestnut is considered as having interesting characteristics. Chestnuts are among the main sources of starch (up to $70 \%$ ) but contain low amounts of protein $(2-4 \%)$ and fat $(2-5 \%)$ (Vaughan \& Geissler, 1997a). They present several minerals and vitamins and appreciable levels of fibre (Vaughan \& Geissler, 1997b).

Previous studies on chestnut have concerned the isolation and structural elucidation of a pyrrole alkaloid (Hiermann, Kedwani, Schramm, \& Seger, 2002), determination of sugars (Míguez Bernárdez, De la Montaña Míguelez, \& García Queijeiro, 2004), modification of structure and digestibility of the starch upon cooking (Pizzoferrato, Rotilio, \& Paci, 1999), the effects of roasting on starch, sugars and fatty acid composition and on chestnut quality (Künsch et al., 2001) and the use of cotyledon storage proteins as markers of the genetic diversity within the species 
(Alvarez, Muñoz-Diez, Martín-Cuevas, Lopez, \& Martrn, 2003).

The nature and concentration of organic acids are important factors influencing the organoleptic characteristics of fruit and vegetables, namely their flavour (Vaughan \& Geissler, 1997c). The relative amounts and the presence/ absence of each compound have been considered useful in taxonomic studies (Coppola \& Starr, 1986; Silva, Andrade, Mendes, Seabra, \& Ferreira, 2002; Valentão et al., 2005a), for the determination of percent fruit content in fruit derivatives (Silva et al., 2002) and also to evaluate food processing (Silva et al., 2004a; Valentão et al., 2005b; Wang, Gonzalez, Gbur, \& Aseiage, 1993). Additionally, organic acids may have a protective role against various diseases due to their antioxidant activity (Silva et al., 2004b). To our knowledge, there is no study concerning the organic acids in chestnut.

The main purposes of this study were to determine the organic acids composition of two different chestnut varieties (Judia and Longal) and to investigate the influence of the processing over these compounds. With this aim, chestnut samples collected in Bragança region were subjected to three different procedures (roasting, boiling and frying) and analysed by HPLC/UV.

\section{Materials and methods}

\subsection{Samples}

Samples from two chestnut varieties (Judia and Longal) were collected from the trees of a chestnut orchard (Castanea sativa Miller) in the Bragança region (Northeast of Portugal), in November 2004. Two lots of each variety were separated and immediately transferred to the laboratory. Each lot was divided into four groups: three of them were subjected to three distinct processing methods commonly used for the consumption of chestnut and the fourth one was used as control (Fig. 1). Each sample corresponds to a mixture of 15 chestnuts treated in the same way.

Control samples (samples 1, 2, 3, 4, 17, 18, 19, and 20) were peeled and frozen at $-20{ }^{\circ} \mathrm{C}$. Roasted samples (samples $5,6,7,8,21,22,23$ and 24) were slashed and roasted in an electric oven (Balay, Mod. 508) at $200^{\circ} \mathrm{C}$, for $40 \mathrm{~min}$.
Samples 9, 10, 11, 12, 25, 26, 27 and 28 were slashed and boiled in water $(300 \mathrm{ml})$ for $20 \mathrm{~min}$. Samples 13, 14, 15, $16,29,30,31$ and 32 were slashed and fried in unused edible oil (renewed for each sample), in a frying-pan (Electric CO.FR.1060) at $150^{\circ} \mathrm{C}$, for $7 \mathrm{~min}$. After processing, roasted, boiled and fried samples were peeled and stored in a freezer at $-20^{\circ} \mathrm{C}$.

All the samples were freeze-dried in a Labconco 4.5 apparatus (Kansas City, MO) before analysis, yielding $20 \%$ of dry matter.

\subsection{Standards and reagents}

The standards (oxalic, cis-aconitic, citric, ascorbic, malic, quinic, fumaric, ketoglutaric, succinic, shikimic, pyruvic, malonic and tartaric acids) were from Sigma (St. Louis, MO, USA) and from Extrasynthése (Genay, France). Methanol and hydrochloric acids were obtained from Merck (Darmstadt, Germany) and sulphuric acid from Pronalab (Lisboa, Portugal). The water was treated in a Milli-Q water purification system (Millipore, Bedford, MA, USA).

\subsection{Solid-phase extraction (SPE) columns}

The ISOLUTE C18 non-end-capped (NEC) SPE columns $(50 \mu \mathrm{m}$ particle size, $60 \AA$ porosity; $10 \mathrm{~g}$ sorbent mass $/ 70 \mathrm{ml}$ reservoir volume) were purchased from International Sorbent Technology Ltd. (Mid Glamorgan, UK).

\subsection{Extraction of organic acids}

Organic acids extraction was based on a described procedure (Silva et al., 2002). Each chestnut sample (ca. $5 \mathrm{~g}$ ) was thoroughly mixed with methanol $(5 \mathrm{ml} \times 50 \mathrm{ml})$, at $40{ }^{\circ} \mathrm{C}$. The methanolic extract was filtered and concentrated to dryness under reduced pressure $\left(40^{\circ} \mathrm{C}\right)$. The residue of the methanolic extract was redissolved in acid water ( $\mathrm{pH} 2$ with $\mathrm{HCl})(\mathrm{ca} .50 \mathrm{ml})$ and the aqueous solution was then passed through an ISOLUTE C18 (NEC) column, previously conditioned with $30 \mathrm{ml}$ of methanol and $70 \mathrm{ml}$ of acid water ( $\mathrm{pH} 2$ with $\mathrm{HCl}$ ). The non-polar compounds were retained and the polar ones, such as organic acids, were eluted with the aqueous solution. This aqueous extract was evaporated to dryness under reduced pressure

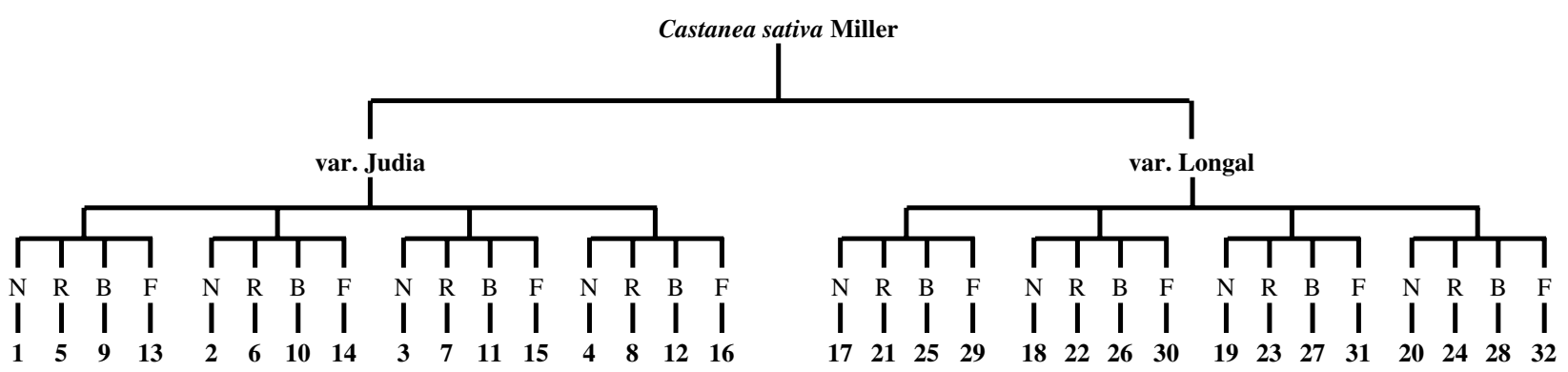

Fig. 1. Schematic representation of chestnut sampling. N: non-treated; R: roasted; B: boiled; F: fried; 1-32: number of the samples. 
$\left(40{ }^{\circ} \mathrm{C}\right)$, redissolved in $0.01 \mathrm{~N}$ sulphuric acid $(1 \mathrm{ml})$ and $20 \mu 1$ were analysed by HPLC/UV.

A standards mixture was prepared by dissolving the compounds in $0.01 \mathrm{~N}$ sulphuric acid and $20 \mu \mathrm{l}$ were analysed by HPLC/UV.

\subsection{HPLC analysis of organic acids}

HPLC analysis was carried out as previously reported (Silva et al., 2002) with some modifications. The separation of organic acids was performed with an analytical HPLC unit (Gilson), using an ion exclusion column Nucleogel ${ }^{\circledR}$ Ion $300 \mathrm{OA}(300 \mathrm{~mm} \times 7.7 \mathrm{~mm})$ column, in conjunction with a column heating device at $30^{\circ} \mathrm{C}$. Elution was carried out at a solvent flow rate of $0.2 \mathrm{ml} / \mathrm{min}$, isocratically, with sulphuric acid $0.01 \mathrm{~N}$ as the mobile phase. Detection was performed with an UV detector set at $214 \mathrm{~nm}$.

Organic acids quantification was achieved by the absorbance recorded in the chromatograms relative to external standards in the standards solution and the peaks were integrated using a default baseline construction technique. Oxalic acid and cis-aconitic acid were quantified together as oxalic acid. Malic acid and quinic acid were quantified together as malic acid.

\subsection{Statistical analysis}

The evaluation of statistical significance was determined by ANOVA followed by Newman-Keuls test. The level of significance was set at $p<0.05$.

\section{Results and discussion}

The HPLC/UV analysis of organic acids showed that both varieties (Judia and Longal) presented a common qualitative profile, composed by seven compounds: oxalic, cis-aconitic, citric, ascorbic, malic, quinic and fumaric acids (Fig. 2(b), Table 1). None of the varieties exhibited ketoglutaric, succinic, shikimic, pyruvic, malonic or tartaric acids. Another compound, trans-aconitic acid, was also found in all of the samples, although in vestigial amounts. However, this compound is considered to be an artefsact, resulting from the rapid isomerisation of cis-aconitic acid (Harborne et al., 1999), a phenomenon also observed with the standards solution (Fig. 2(a)). So, in this work transaconitic acid content was not considered.

The quantification of the identified compounds showed that Longal variety (samples 17-20) had higher organic acids content than Judia (samples 1-4): ca. 251 and $205 \mathrm{mg} / \mathrm{kg}$, respectively (Table 1). In both Judia and Longal varieties ascorbic acid was the compound present in the highest amount, representing ca. $42.6 \%$ and $37.0 \%$ of total acids, respectively (Fig. 3). Fumaric acid was the minor organic acid, corresponding to ca. $0.2 \%$ and $0.4 \%$ of total compounds in Judia and Longal varieties, respectively (Fig. 3). Some differences were noticed in the quantitative profiles. Judia variety showed a tendency for higher citric
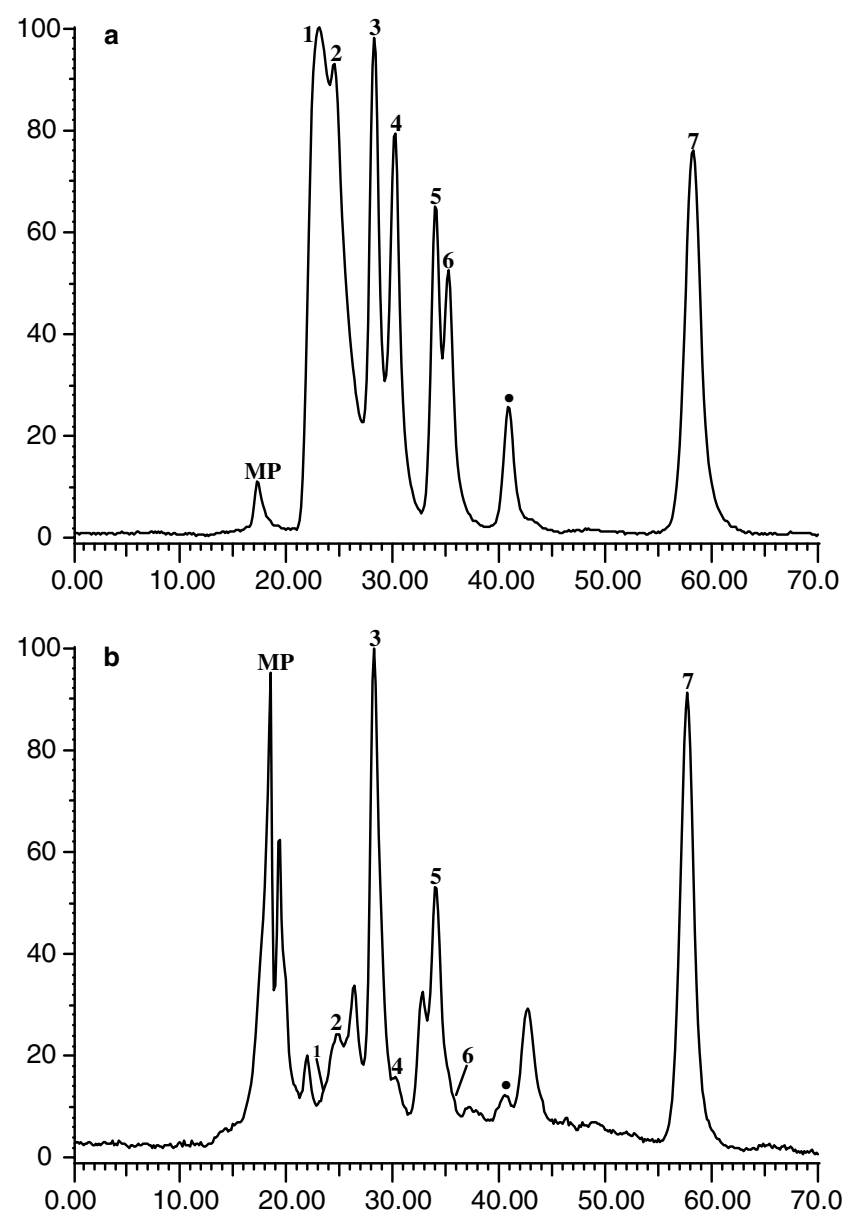

Fig. 2. HPLC/UV chromatogram: (a) standards solution and (b) chestnut (non-treated sample). Detection at $214 \mathrm{~nm}$. (MP) mobile phase; (1) oxalic acid; (2) cis-aconitic acid; (3) citric acid; (4) ascorbic acid; (5) malic acid; (6) quinic acid; (7) fumaric acid; (๑) trans-aconitic acid.

acid contents than Longal (ca. $34.8 \%$ and $28.4 \%$ of total acids, respectively) (Fig. 3). Additionally, the content of the pair malic plus quinic acids was significantly higher in Longal variety, corresponding to ca. $33.0 \%$ of total compounds, while in Judia variety it represented ca. $21.5 \%$ of total acids (Fig. 3). These results suggest that the relative amounts of the pair malic plus quinic acids may be useful for the discrimination of these two Portuguese chestnut varieties.

Roasting, boiling and frying treatments lead to a significant decrease of the total organic acids contents of the two varieties, with fried chestnuts exhibiting the higher losses of compounds (ca. 127 and $155 \mathrm{mg} / \mathrm{kg}$ in Judia and Longal varieties, respectively). Thus, heat appears to be the main cause of modification of the organic acids contents of chestnut samples, while hydrolytic reactions of organic acids complexes seem not to interfere. In a general way, the total acids content decreased mainly due to the reduction of citric and ascorbic acids. Fumaric acid, which was already a minor compound in both varieties, completely disappeared or was reduced to very low amounts upon each treatment (Table 1). The loss of citric and ascorbic 
Table 1

Organic acids composition of chestnut ( $\mathrm{mg} / \mathrm{kg}$, dry basis) ${ }^{\mathrm{a}}$

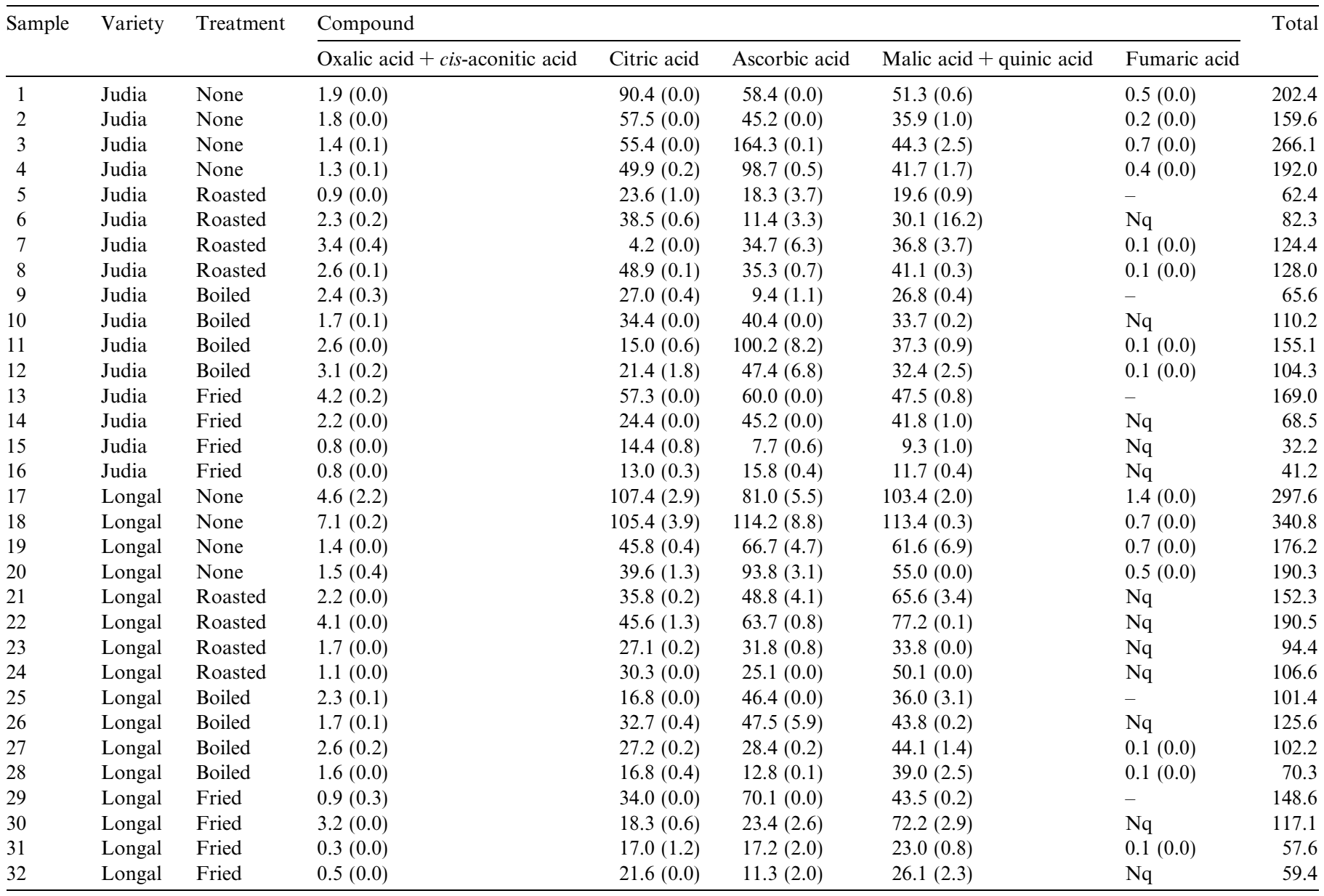

Nq: not quantified.

${ }^{\text {a }}$ Results are expressed as mean (standard deviation) of four determinations.
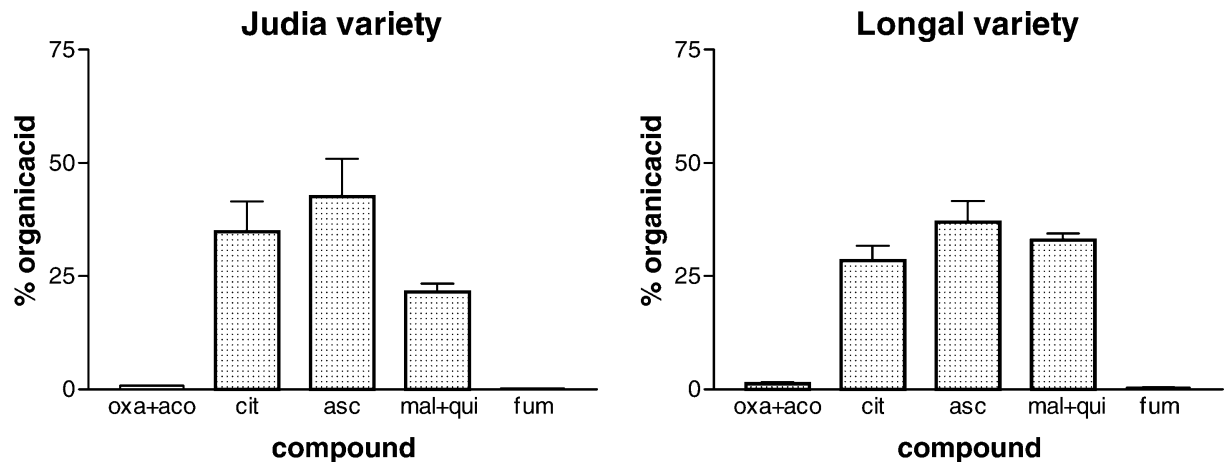

Fig. 3. Organic acids profile of Judia and Longal variety chestnuts. (oxa) oxalic acid; (aco) cis-aconitic acid; (cit) citric acid; (asc) ascorbic acid; (mal) malic acid; (qui) quinic acid; (fum) fumaric acid.

acids seems to indicate that these acids are more sensitive to the high temperatures used during processing, a behaviour already described (Silva et al., 2004a).

As far as we know, this is the first report concerning the organic acids composition of Longal and Judia varieties of chestnut. The work herein also indicates that roasting, boil- ing and frying processes affect the chemical composition of this nut, which may be important when nutritional and healthy aspects are considered. The results obtained seem to indicate that organic acid profile is a tool that deserves to be explored for the discrimination of varieties and also for evaluating the processing of these fruits. 


\section{References}

Alvarez, J. B., Muñoz-Diez, C., Martín-Cuevas, A., Lopez, S., \& Martín, L. M. (2003). Cotyledon storage proteins as markers of the genetic diversity in Castanea sativa Miller. Theoretical and Applied Genetics, 107, 730-735.

Coppola, E. D., \& Starr, M. S. (1986). Liquid chromatographic determination of major organic acids in apple juice and cranberry juice cocktail: collaborative study. Journal of the Association of Official Analytical Chemists, 69, 594-597.

Goulão, L., Valdiviesso, T., Santana, C., \& Oliveira, C. M. (2001). Comparison between phenetic characterisation using RAPD and ISSR markers and phenotypic data of cultivated chestnut (Castanea sativa Miller). Genetic Resources and Crop Evolution, 48, 329-338.

Harborne, J. B., Baxter, H., \& Moss. G. P. (1999). Phytochemical dictionary: A handbook of bioactive compounds from plants (second ed., p. 33). London: Taylor \& Francis.

Hiermann, A., Kedwani, S., Schramm, H. W., \& Seger, C. (2002). A new pyrrole alkaloid from seeds of Castanea sativa. Fitoterapia, 73, 22-27.

Künsch, U., Schärer, H., Patrian, B., Höhn, E., Conedera, M., Sassella, A., et al. (2001). Effects of roasting on chemical composition and quality of different chestnut (Castanea sativa Miller) varieties. Journal of the Science of Food and Agriculture, 81, 1106-1112.

Míguez Bernárdez, M., De la Montaña Míguelez, J., \& García Queijeiro, J. (2004). HPLC determination of sugars in varieties of chestnut fruits from Galicia (Spain). Journal of Food Composition and Analysis, 17, 63-67.

Pizzoferrato, L., Rotilio, G., \& Paci, M. (1999). Modification of structure and digestibility of chestnut starch upon cooking: a solid state ${ }^{13} \mathrm{C} \mathrm{CP}$ MAS NMR and enzymatic degradation study. Journal of Agricultural and Food Chemistry, 47, 4060-4063.
Silva, B. M., Andrade, P. B., Gonçalves, A. C., Seabra, R. M., Oliveira, M. B., \& Ferreira, M. A. (2004a). Influence of jam processing upon the contents of phenolics, organic acids and free amino acids in quince fruit (Cydonia oblonga Miller). European Food Research and Technology, 218, 385-389.

Silva, B. M., Andrade, P. B., Mendes, G. C., Seabra, R. M., \& Ferreira, M. A. (2002). Study of the organic acids composition of quince (Cydonia oblonga Miller) fruit and jam. Journal of Agricultural and Food Chemistry, 50, 2313-2317.

Silva, B. M., Andrade, P. B., Valentão, P., Ferreres, F., Seabra, R. M., \& Ferreira, M. A. (2004b). Quince (Cydonia oblonga Miller) fruit (pulp, peel, and seed) and jam: antioxidant activity. Journal of Agricultural and Food Chemistry, 52, 4705-4712.

Valentão, P., Andrade, P. B., Rangel, J., Ribeiro, B., Silva, B. M., Baptista, P., et al. (2005b). Effect of the conservation procedure on the contents of phenolic compounds and organic acids in chanterelle (Cantharellus cibarius) mushroom. Journal of Agricultural and Food Chemistry, 53, 4925-4931.

Valentão, P., Lopes, G., Valente, M., Barbosa, P., Andrade, P. B., Silva, B. M., et al. (2005a). Quantitation of nine organic acids in wild mushrooms. Journal of Agricultural and Food Chemistry, 53, $3626-3630$.

Vaughan, J. G., \& Geissler, C. A. (1997a). The new Oxford book of food plants (p. 30). New York: Oxford University Press.

Vaughan, J. G., \& Geissler, C. A. (1997b). The new Oxford book of food plants (p. 216). New York: Oxford University Press.

Vaughan, J. G., \& Geissler, C. A. (1997c). The new Oxford book of food plants (p. xix). New York: Oxford University Press.

Wang, T., Gonzalez, A. R., Gbur, E. E., \& Aseiage, J. M. (1993). Organic acids changes during ripening of processing peaches. Journal of Food Science, 58, 631-632. 